\title{
Function Spreading in Coordinate Structures
}

\begin{abstract}
We propose an analysis in LFG of a particular asymmetric sentential coordination pattern in Welsh. ${ }^{1}$ In this construction, the main verb of the first clause is marked for tense and the remaining conjuncts have non-finite verb forms. This single instance of tense marking (occurring on the finite verb of the first conjunct) is however semantically interpreted with respect to each conjunct. The coordinate structure also shares a single subject. The LFG approach to constituent coordination (a) posits an exocentric (or multiply-headed) coordinate schema at c-structure and (b) interprets coordinate structures as sets at f-structure. In this paper we show how this general approach to sentential coordination in LFG can provide a simple and straightfoward analysis of this tense and subject asymmetric coordination pattern found in Welsh. We extend the constituent coordination schema to coordinate IP and VP, and postulate explicit "spreading" equations for the shared information. We show that the spreading analysis is also motivated by similar data from a range of typologically diverse languages. Finally we show how the approach is superior to an alternative involving VP level coordination, with the finite verb in I and the subject DP nodes outside the structural scope of coordination.
\end{abstract}

\footnotetext{
${ }^{1}$ I am grateful to Joan Bresnan, Mary Dalrymple, Anette Frank and Rachel Nordlinger for comments on a previous draft and similarly to the audience at a King's College London linguistics seminar and participants in the 4th Celtic Linguistics Conference for useful discussion.
} 


\section{Introduction}

This paper is concerned with a type of asymmetric coordination in Welsh in which only the verb of the first conjunct is marked for tense, with the verbs of the second and any following conjuncts occurring in the non-finite (verbnoun) form. Despite the lack of overt tense marking, non-initial conjuncts are interpreted as tensed, and thus it seems that a single instance of tense marking is semantically interpreted with respect to each conjunct.

(1) Cododd Gwilym ei docyn a rhedeg amy trên. buy-PAST.3S Gwilym his ticket and run for the train. 'Gwilym bought his ticket and ran for the train.' (Thomas 1996:462)

(2) Daeth ei wraig ynôl, a sefyddfel llewes uwch ei ben. come-PAST.3S 3SM wife back, and stand like lioness over his head. His wife returned, and stood like a lioness over him (Thorne 1993:327)

As well as sharing tense, in this construction the conjuncts also obligatorily share a single subject, expressed in the first conjunct by a full DP, as in examples (1)-(2) above, or by verbal inflection (pronominal incorporation), as in (3) and (4).

(3) Aethant i'r tŷ ac eistedda bwyta. go-PAST.3PL to-the house and sit and eat 'They went to the house, sat down and ate.' (Rouveret 1994:302)

(4) Syrthiasant $i$ freichiau ei gilydd a cherdded allan o'r fall-PAST.3PL to arms each other and walk out from-the fynwent gyda'e gilydd. cemetery with-each other 
Function Spreading in Coordinate Structures:December 11, 2003:

They fell into each other's arms and walked from the cemetery together.'

(Thorne 1993:63)

This pattern stands in contrast to the following type of sentential coordination in which there is a tensed verb in each conjunct.

(5) Peidiodd $\hat{a}$ meddwlac aeth ynôl. cease-PAST.3S with think and go.PAST.3s back.

She stopped thinking and returned (Thorne 1993:335)

This paper develops an analysis of this coordination pattern in terms of the standard approach to coordination in LFG in combination with explicit "spreading" or concord equations to share tense and subject information across the members of the coordinate structure. The rest of this paper proceeds as follows. Section 2 outlines the constituent structures which we will assume for Welsh finite clauses, while section 3 introduces the LFG approach to consitutent coordination through discussion of a number of sentential coordination patterns in Welsh. Section 4 presents the analysis. In section 5 we discuss data from other typologically different languages which share the properties of the Welsh construction that we are dealing with, and which are amenable to the same style of analysis. Before concluding, section 6 considers an alternative analysis and shows that it faces a range of difficulties which do not occur for the analysis presented here. 


\section{Welsh Constituent Structure}

Welsh is strongly head initial, and in both simple and periphrastic finite clauses the finite verb is initial, followed by the subject. The periphrastic clausal pattern, illustrated in (6) and (7), involves the combination of a finite verb with one or more non-finite verbal forms (and in the case of aspectually specified clauses, one or more aspectual particles). These (non-finite) verbal elements precede any complements but follow the subject. For clauses of this type I posit an $\left.{ }_{I P} \mathrm{I}-\mathrm{S}\right]$ structure, with subject preceding the main predicate in $\mathrm{S}$ and finite verbs occurring in I (see Bresnan 2000 and Kroeger 1993 for discussion of these structural assumptions). The structure

for (7), together with the functional annotations on c-structure nodes which partly specify the mapping to f-structure, is given in (8).

(6) Gwnaeth Siôn weld draig. did-PAST.3S John see dragon 'John saw a dragon.' (Sproat:1985,176)

(7) Mae Mairyn prynutatws o'r siop. be.PRES.3s Mair PROG buy potatoes from-the shop. 'Mair buys/is buying potatoes from the shop.' 
(8)
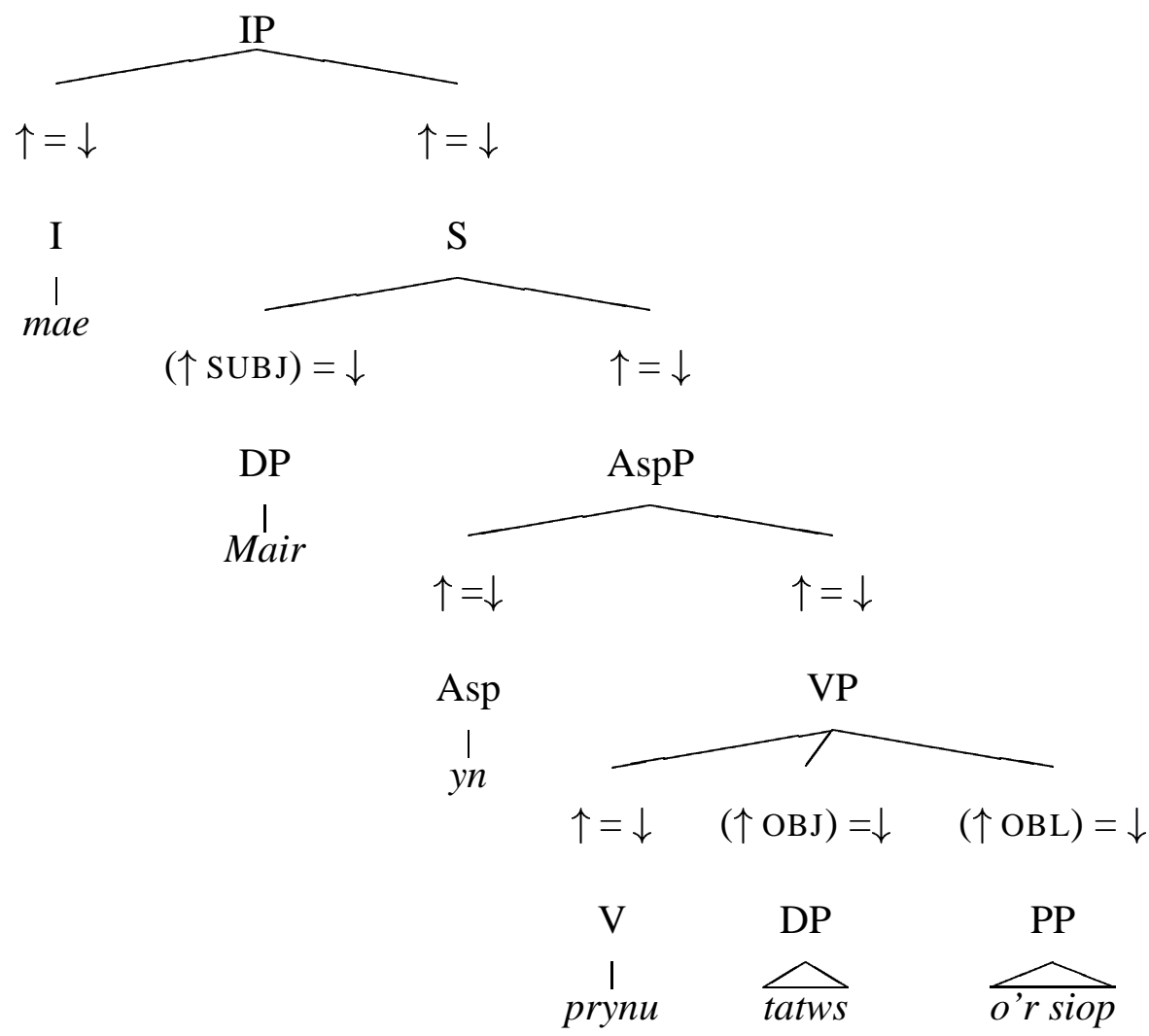

The simple clausal pattern involves only a single finite verb and no non-finite verb forms. The finite verb is also initial in this clausal pattern, followed by the subject. Again, I follow Kroeger (1993) and Bresnan (2001) in locating the finite verb in I and taking the structural complement of I to be S. ${ }^{2}$

(9) Gwadodd y carcharory drosedd yn gwbl. deny-PST.3s the prisoner the offence completely. 'The prisoner denied the offence completely.' (Thorne 1993:214)

\footnotetext{
${ }^{2}$ An alternative, less hierarchical, representation of Welsh constituent structure is taken in Borsley (REFS), in which for example simple VSO clauses are treated essentially as ${ }_{s} \mathrm{~V}$ NP NP ]. The analysis of the tense and subject shared coordinate construction which we propose here is basically independent of these details of constituent structure, and would carry over straightforwardly to these alternative structural assumptions. For these reasons, we do not discuss constituent structure in any great detail here.
} 
(10)
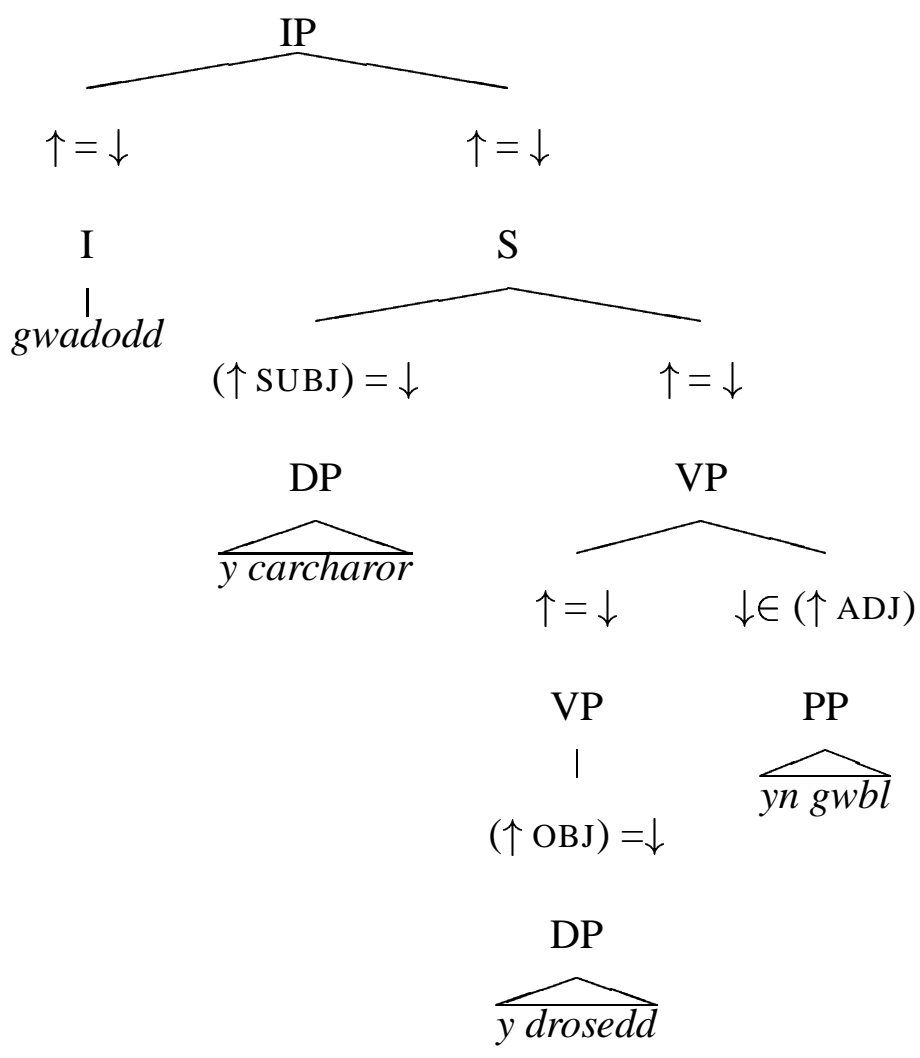

To those unfamiliar with LFG a tree such as (10) might looks a little strange, since it lacks a V within the VP, and therefore might appear to violate principles of endocentricity. In LFG, since both IP and VP map to the same f-structure, the finite verb in I serves directly as the (extended) head of VP and thus it is unnecessary to postulate a $\mathrm{V}_{t}$ (and by the Principle of Economy such unmotivated c-structure is not permitted). The principles of endocentricity are therefore maintained in such structures. ${ }^{3}$

\footnotetext{
${ }^{3}$ The definition of extended head specifies that, amongst those nodes in the inverse image of $\phi(\mathrm{VP})$, the closest nondominating node to VP is identified as the head:

(11) Definition of Extended Head: Given a c-structure containing nodes $\mathcal{N}, \mathcal{C}$ and c- to f-structure correspondence mapping $\phi, \mathcal{N}$ is an extended head of $\mathcal{C}$ if $\mathcal{N}$ is the is the minimal node in $\phi^{-1}(\phi(\mathcal{C}))$ that c-commands $\mathcal{C}$ without dominating $\mathcal{C}$ (Bresnan 2001:132)
} 


\section{LFG Analysis of Welsh Sentential Coordination}

This section provides a brief overview of the various coordination patterns available in Welsh, and shows how they are straightforwardly captured in the LFG analysis of coordination. First, as the examples below show, it is possible to coordinate complete IP clauses in Welsh:

(12) Mae Mairyn cysgua mae Johnyn palu'r ardd. be.PRES.3S Mair PROG sleep and is John PROG dig-the garden 'Mary is sleeping and John is digging the garden.'

(13) Mae Mair yn crio ond mae John yn chwerthin. be.PRES.3S Mair PROG cry but is John PROG laugh 'Mary is crying but John is laughing.'

(14) Peidiodd $\hat{a}$ meddwlac aeth ynôl. cease-PAST.3S with think and go.PAST.3s back. She stopped thinking and returned (Thorne 1993:335)

The analysis of coordinate structures such as these is very straightforward in LFG. Coordinate structures are treated as sets at f-structure, and licensed by a general coordination schema at c-structure (the annotated c-structure rule in (15) can therefore be seen as an instance of this more general schema, but for concreteness I spell out all specific instantiations in this paper). (16) shows the tree structure corresponding to the coordination in (12), together with the functional annotations associated with the coordination schema. 


$$
\mathrm{IP} \rightarrow \text { IP } \quad \text { Conj IP }
$$

$$
\downarrow \in \uparrow \quad \uparrow=\downarrow \quad \downarrow \in \uparrow
$$

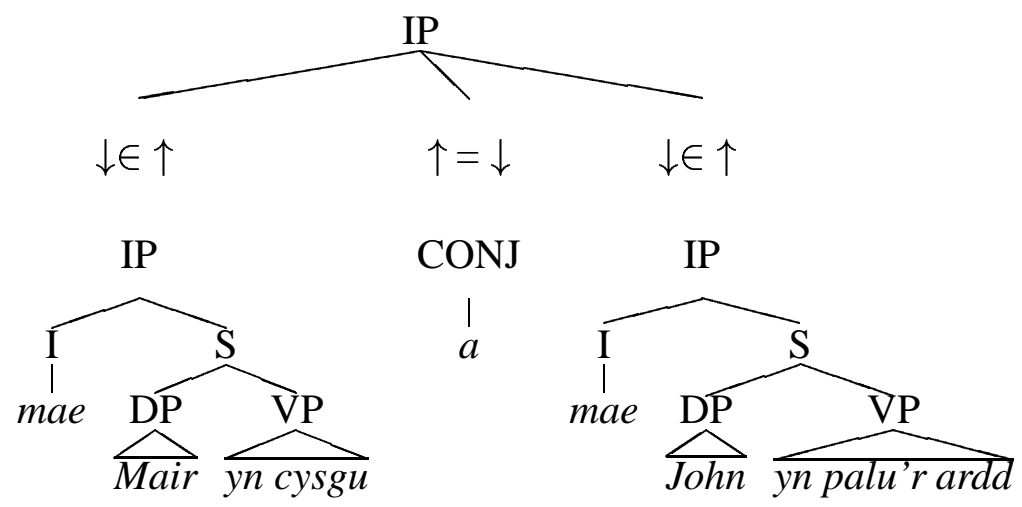

The annotation $\downarrow \in \uparrow$ (on the daughter IPs) states that the f-structure of the IP is a member of the set of f-structures corresponding to the coordinate structure as a whole. The f-structure for (16) is shown in (17) below. Notice that information associated with the CONJ node is contributed directly to the set itself.

$$
\left[\left\{\begin{array}{l}
{\left[\begin{array}{lll}
\text { CONJ AND } & \text { 'SLEEP }\langle(\text { SUBJ })\rangle \\
\text { TENSE } & \text { PRES } \\
\text { ASP } & \text { PROG } \\
\text { SUBJ } & {\left[\begin{array}{ll}
\text { PRED } & \text { 'MAIR' }
\end{array}\right]}
\end{array}\right]} \\
{\left[\begin{array}{lll}
\text { PRED } & \text { 'DIG }\langle(\text { SUBJ })(\mathrm{OBJ})\rangle \\
\text { TENSE } & \text { PRES } \\
\text { ASP } & \text { PROG } \\
\text { OBJ } & {\left[\begin{array}{ll}
\text { PRED } & \text { 'GARDEN' } \\
\text { SPEC } & \text { DEF }
\end{array}\right]}
\end{array}\right\}}
\end{array}\right.\right.
$$


Function Spreading in Coordinate Structures:December 11, 2003:

As well as coordinating full IPs, it is also possible to coordinate Ss under a shared

finite verb (as before, the tree shows only the functional annotations on the higher nodes): $:^{4}$

(19) 'Roedd Mairyn canu'r delyna Johnyn dawnsio. be.IMPF.3S Mair PROG sing-the harp and John PROG dance.

Mair was playing the harp and John was dancing.

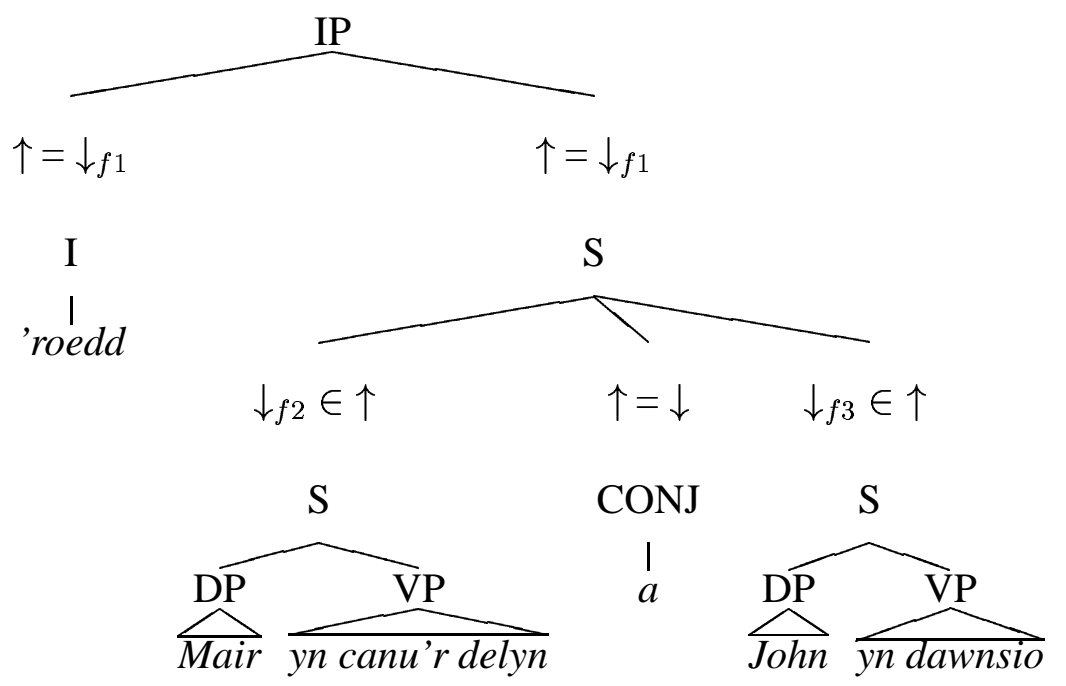

Again, these structures are licensed by an instantiation of the general coordination schema:

$$
\mathrm{S} \rightarrow \mathrm{S} \quad \text { Conj } \mathrm{S}
$$

$$
\downarrow \in \uparrow \quad \uparrow=\downarrow \quad \downarrow \in \uparrow
$$

\footnotetext{
${ }^{4}$ In these structures the verbnoun, where the same, can be gapped, as shown in the example below.

(18) 'Roedd Mairyn canu'r delyn, Gwily gitar, Gwen y piano a John yn dawnsio. was Mair PRT sing-the harp, Gwil the guitar, Gwen the piano and John PRT dance 'Mair was playing the harp, Gwil the guitar, Gwen the piano and John was dancing.'
}

We will not be concerned with gapping in this paper. 
Function Spreading in Coordinate Structures:December 11, 2003:

As in the IP example, the annotation $\downarrow \in \uparrow$ specifies that the f-structures of the daughter $\mathrm{S}$ nodes are members of the set of f-structures corresponding to the mother $\mathrm{S}$ node. F-descriptions associated with nodes and lexical elements within the daughter $\mathrm{S}$ nodes will therefore be contributed to the member f-structures ( $f 2$ and $f 3$ respectively). On the other hand, information (f-descriptions) associated with the lexical material under the I and Comp nodes is contributed directly to the set $(f 1)$ itself. What this means depends on the nature of the feature itself, for LFG makes a distinction between distributive and non-distributive features. As we have seen, the features CONJ and PRECONJ are non-distributive, and are thus defined for the set itself, as shown in (20) above. Most other features, including for example the governable grammatical functions (SUBJ, OBJ and so on) are distributive. Consequently, the information associated with roedd that is, (TENSE and SUBJ) information, is distributed across the coordinate structure to the members of the set of f-structures, because these features are themselves distributive.

(22) If $\alpha$ is a distributive feature and $s$ is a set of f-structures, then $(s a)=v$ holds if and only if $(f a)=v$ for all f-structures $f$ that are members of the set $s$ (Dalrymple 2001:365)

The f-structure corresponding to (19) is (23). 
Function Spreading in Coordinate Structures:December 11, 2003:

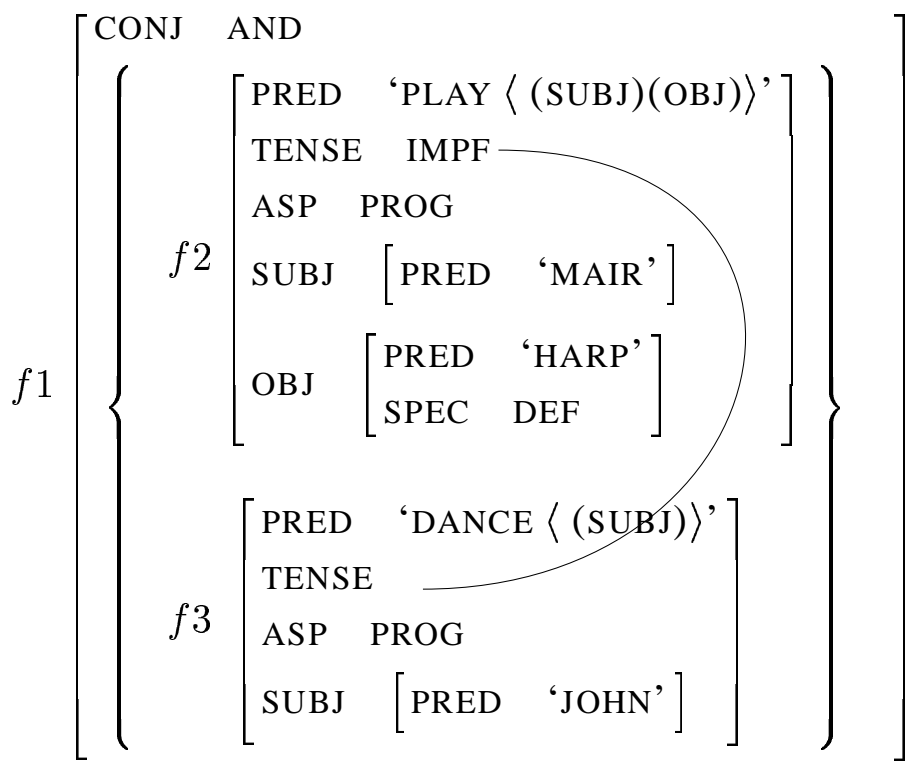

Finally, it is also possible to coordinate at levels lower within the clause, conjoining

AspPs or VPs under a shared finite verb and subject. ${ }^{5,6}$

'Roedd Maira Johnyn dawnsio ac yn canu.

be.IMPF.3S Mair and John PROG dance and sing

'Mair and John were singing and dancing.'

\footnotetext{
${ }^{5}$ In (26), a third person singular finite verb occurs with a plural coordinate subject. Note that the lack of number agreement here is not an indication of partial agreement under coordination but a more general fact about the nature of the agreement system in Welsh: non-pronominal plural subjects (in situ) always occur with the 3rd singular form of the finite verb, which therefore has the status of a default. We take it that the default $3 \mathrm{~s}$ form of the verb does not place a syntactic constraint on the subject's number and hence no feature clash arises.

${ }^{6}$ These examples illustrate the instantiations of the general coordination schema shown below in (24) and (25) for completeness. Notice that the placement of the Preconj and Conj words delimits the structural scope of coordination in example (27).
}

$$
\begin{aligned}
& \text { AspP } \rightarrow \text { AspP Conj AspP } \\
& \downarrow \in \uparrow \quad \uparrow=\downarrow \quad \downarrow \in \uparrow \\
& \text { AspP } \rightarrow \text { Preconj AspP Conj AspP } \\
& \uparrow=\downarrow \quad \downarrow \in \uparrow \quad \uparrow=\downarrow \quad \downarrow \in \uparrow
\end{aligned}
$$


Function Spreading in Coordinate Structures:December 11, 2003:

y byddai hi naillai'n marw'n ifanc neu'n colli'r

PT be.COND.3s she either-PROG die-PT young or-PROG lose-the weledigaeth

vision

'She would either die young or lose her vision.'

(28)
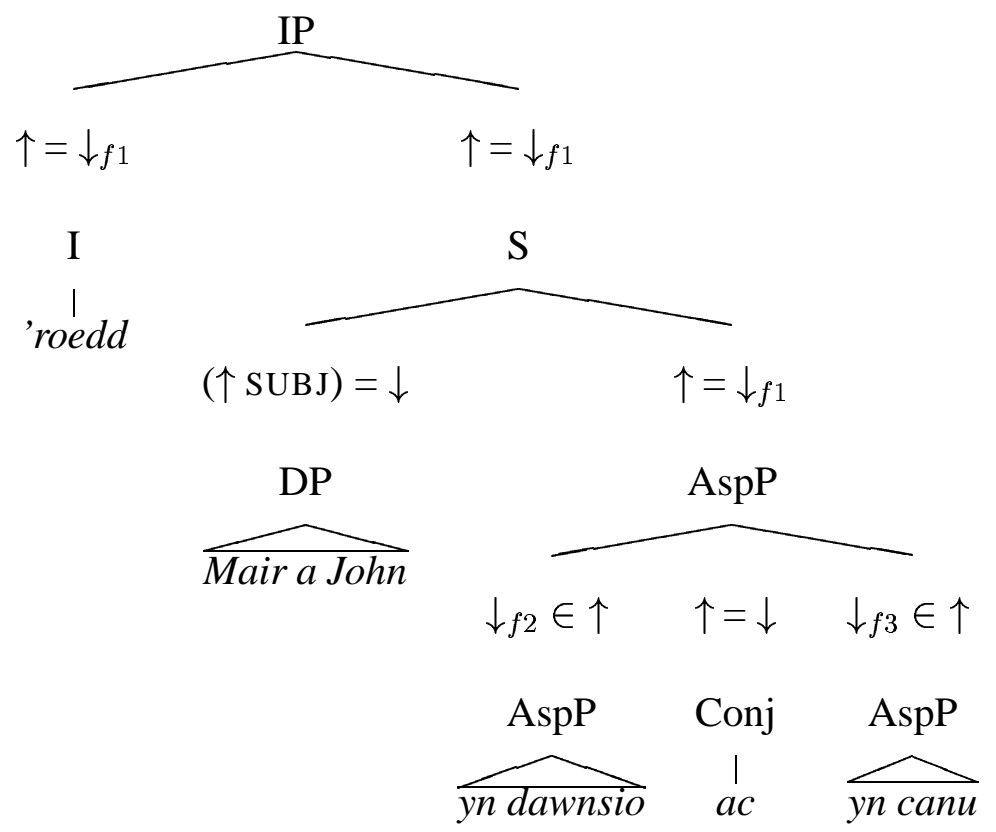

(29)

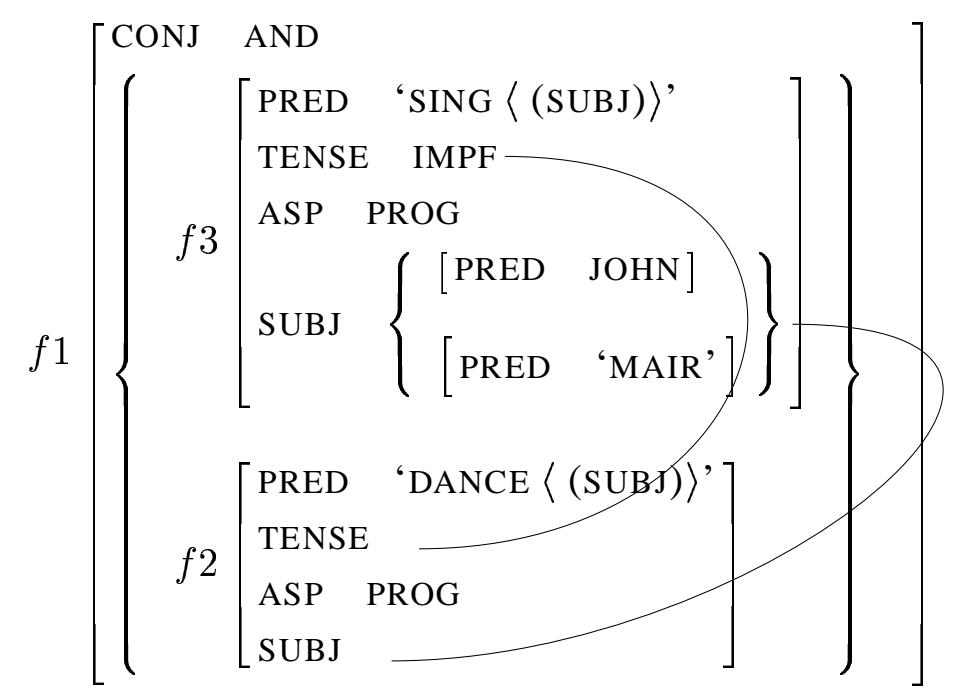

To complete the picture, (30) is a case of VP coordination (in the complement of a modal verb, which we treat as a control predicate). Note that it follows without 
Function Spreading in Coordinate Structures:December 11, 2003:

further stipulation that the SUBJ information contributed by an element outside the coordinate structure is distributed across the members of the set of f-structures which form the XCOMP (not all details are shown in the f-structure below).

(30) Ellwch chi aros fan hyn neu ddod'da ni. can.PRES.2S you stay by here or come with 1PL 'You can stay here or come with us.'
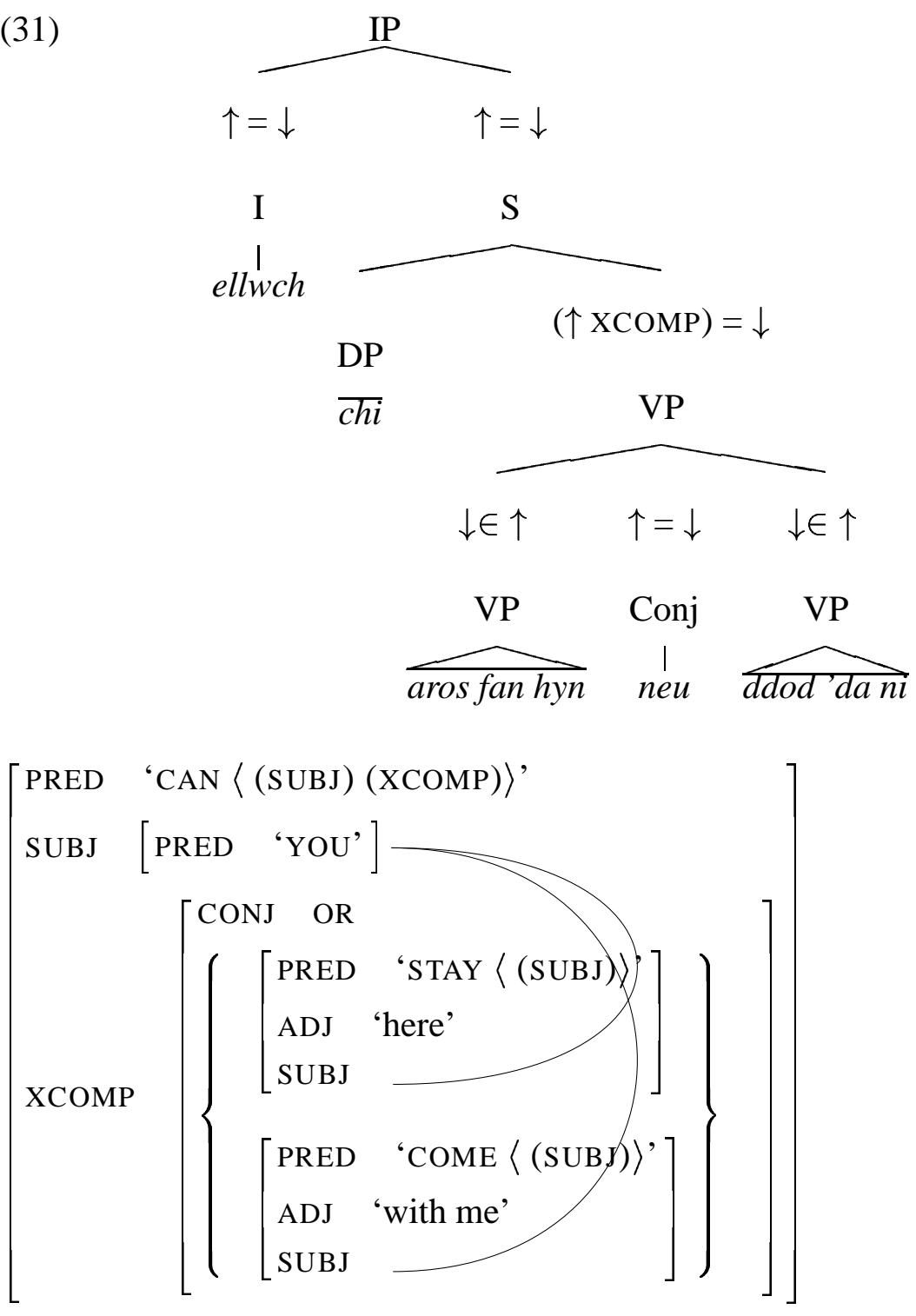


\section{Analysing Asymmetric Coordination}

We are now in a position to return to the data briefly introduced in section 1 and propose an analysis of this asymmetric coordinate construction. Recall that the key features of this construction are firstly, that only the first (VSO) clause is marked for tense, but the tense is interpreted with respect to each clause, secondly, that unlike the tense information, the lexical meaning of the initial (inflected) verb relates only to the first conjunct (suggesting that only some of the information associated with the finite verb 'spreads' into the other conjuncts), and thirdly, that the subject occurring after the tensed main verb in the first conjunct is interpreted with respect to each conjunct or clause, with no subject being expressed in the second and any subsequent clause. For example in (32), both conjuncts share the subject $y$ ffermwr and the verb of the first conjunct is a past tense form while the verb of the second conjunct is the non-finite (verbnoun) form. Note that although the construction appears to be much more frequent in the past tense, the examples in (36) and (37) show that it is not restricted to past tense narratives.

(32) Aeth y ffermwraty drwsa churo arno. go-PAST.3s the farmer to the door and knock on-3SM 'The farmer went to the door and knocked on it.' (Rouveret 1994:302)

(33) Gwthiodd Margaret Rose y llyfr i'w baga thynnu'r sip arno. push-PAST.3s Margaret Rose the book in-her bag and close-the zip on it Margaret Tose pushed the book into her bag and closed the zip on it (Thorne $1993: 328)$ 
Function Spreading in Coordinate Structures:December 11, 2003 :

(34) Rhedodd y plant i mewn ac eistedd wrthy bwrdd. run-PAST.3s the children in and sit at the table 'The children ran in and sat down at the table (King 1993:198)

(35) Godes i’n gynnara mynd am dro. get up-PAST.1s 1S-PRT early and go for walk. 'I got up early and went for a walk.' (King 1993: 198)

(36) Osawn ni yno a cwyno, efallai y byddan nhw'n if go.FUT.1 PL 1PL there and complain, perhaps PT be-FUT.3PL 3PL-PROG gwrando

listen

If we go there and complain, perhaps they'll listen.' (King 1993: 198)

(37) Wethwn ni'r hen dy 'ma a chodi un newyddyn yn cae sell-FUT.1 PL 1 PL-the old house there and build one new in the field wrth ymyl.

by edge.

We'll sell this old house and build another one in the next field (ibid)

Our starting point in considering the analysis of sentences like (32) - (37) is the observation that this construction should be treated as a coordination at f-structure, rather than as involving some form of adjunctival modification of the first clause. That is, this construction, like those discussed in the previous section, has the semantics of a (type of) coordination, and thus we would expect the f-structure of an example such as (32) to be a set of f-structures, in which subject and tense values are shared or distributed across each conjunct, as in (38). 


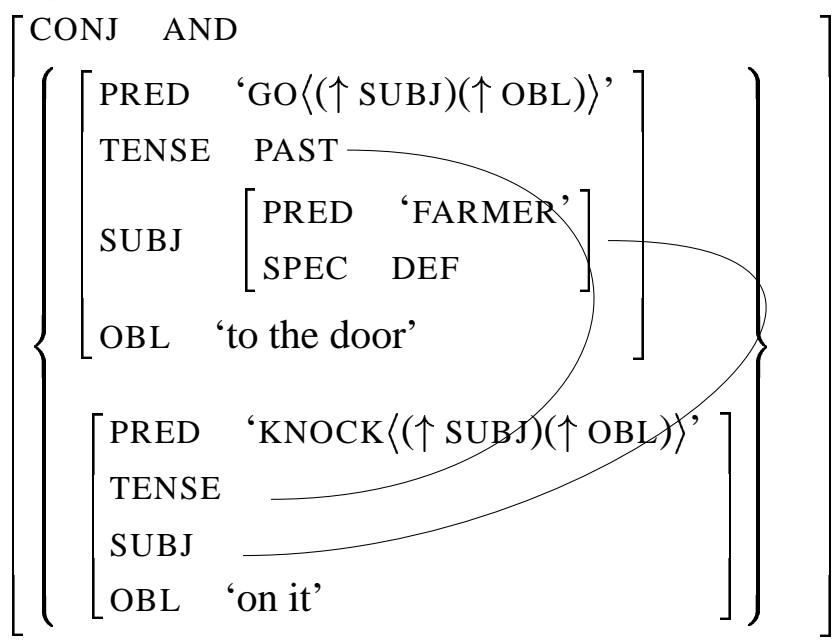

Of course, this distribution of SUBJ and TENSE attributes would follow automatically from the theory of features and coordination outlined in section 3 if the finite verb and subject were outside the structural scope of coordination, that is if these constructions involved coordination at the level of VP, along the lines of the analysis of (26) shown in (28) above. There are, however, several reasons for concluding that this analysis would not be correct.

Notice first that in the case of the coordination of periphrastic clauses, such as (26), all the information associated with the finite auxiliary (which is outside the structural scope of coordination) does in fact distributes across all the conjunct, while in the case of the asymmetric coordinate construction under discussion here, this is not so. The tensed verb is a main verb (rather than an auxiliary) and thus has a PRED value which is appropriate only for the f-structure of the first conjunct. If the finite verb were outside the scope of coordination, along the lines of (28), then the PRED feature 
Function Spreading in Coordinate Structures:December 11, 2003:

would also be (incorrectly and incoherently) distributed. ${ }^{7}$ A related observation is

that positing a structural asymmetry for these examples would entail claiming, in theories which explicitly raise $\mathrm{V}$ to I to host tense marking, that these constructions involve $\mathrm{V}$ movement out of the first conjunct in a coordinate structure, in violation of well established constraints. ${ }^{8}$

Together, these observations suggest an analysis of this construction in terms of unlike constituent coordination in c-structure, involving the coordination of an initial IP conjunct with VP sisters, with explicit sharing of f-structure attributes across the conjuncts. ${ }^{9}$ That is, the example in (32), repeated here as (39), has the c-structure shown in (40).

(39) Aeth y ffermwraty drwsa churo arno. go-PAST.3S the farmer to the door and knock on-3SM 'The farmer went to the door and knocked on it.' (Rouveret 1994: 302)

\footnotetext{
${ }^{7}$ This would lead to a clash of PRED values for the non-initial conjuncts, and no grammatical f-structure would result.

${ }^{8}$ Of course, as a non-derivational syntactic theory LFG does not posit V-movement, so this issue arises in a slightl different, but equivalent form. No V-movement is involved in the structures associated with VSO sentences, but it follows from the principles of endocentricity that when a VP lacks an overt c-structure head, an appropriate (functional) category must serve as its extended head. The definition of extended head (see footnote 3 above) does not permit the finite verb in I to serve as the extended head of the first conjunct VP, which therefore lacks a head.

${ }^{9}$ Although we refer to this as unlike constituent coordination, of course VP and IP differ only in the presence of a feature $+\mathrm{F}$ (marking functional categories) in the feature matrix of IP: other than this feature, it shares the feature matrix of VP.
} 
(40)

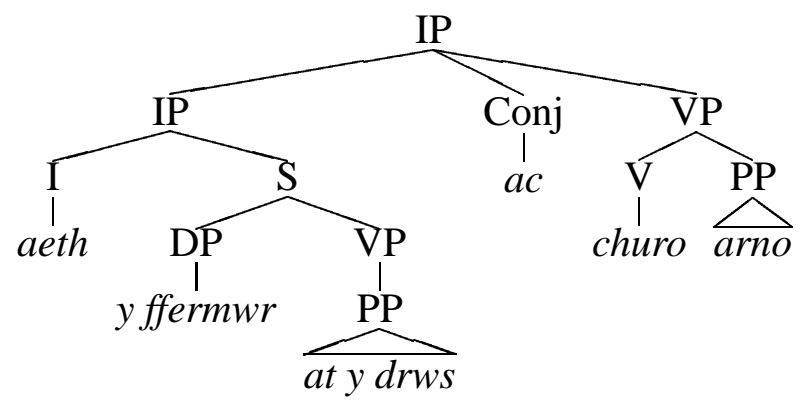

The coordinate daughters are annotated $\downarrow \in \uparrow$, as expected on the basis of the general coordination schema, and further annotations on the first conjunct 'spread' the TENSE and SUBJ features.

$$
\begin{aligned}
& \mathrm{IP} \rightarrow \text { IP Conj VP } \\
& \downarrow \in \uparrow \quad \uparrow=\downarrow \quad \downarrow \in \uparrow \\
& (\downarrow \text { TENSE })=(\uparrow \text { TENSE }) \\
& (\downarrow \mathrm{SUBJ})=(\uparrow \mathrm{SUBJ})
\end{aligned}
$$

The annotated tree is shown in (42) below. The existence of these two sharing equations constitutes the language specific annotation which permits the tense and subject shared coordinate pattern in Welsh. 


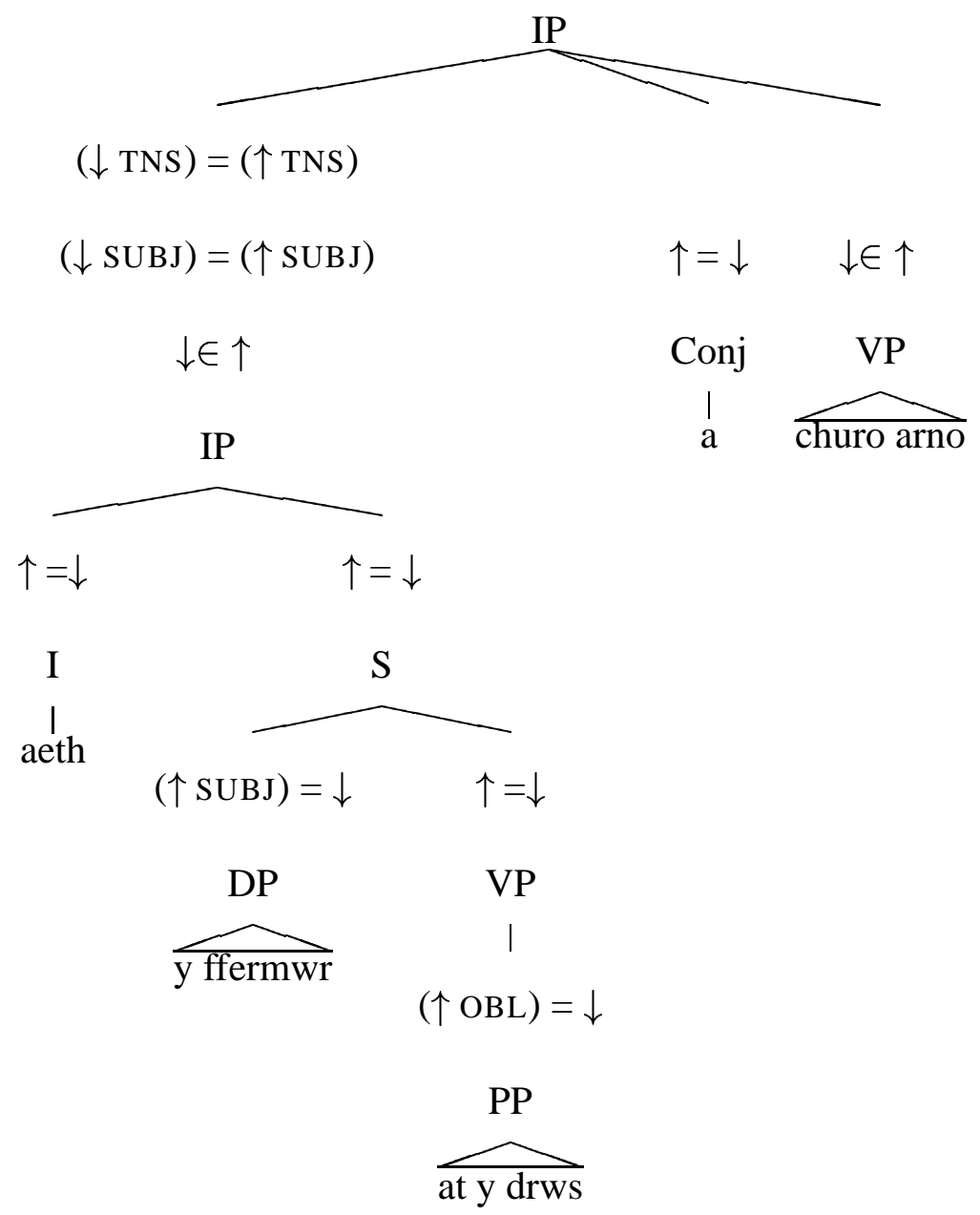

The f-description $(\downarrow$ SUBJ $)=(\uparrow$ SUBJ $)$ identifies the f-structure which is the SUBJ of the first conjunct with the SUBJ of the coordination as a whole. Because SUBJ is a distributive feature (alongside other grammatical functions) it follows that the SUBJ values of all conjuncts are identified. In this way, the SUBJ is shared across the conjuncts. The TENSE information is shared in precisely similar fashion. The tense and subject shared coordination pattern in Welsh is therefore captured by means 
Function Spreading in Coordinate Structures:December 11, 2003:

of these two simple equations. ${ }^{10}$ In the following section, we consider data from other languages for which an analysis in terms of explicit feature spreading is also motivated.

\section{Other Languages}

\subsection{Tense Spreading}

The phenomenon of tense spreading is by no means restricted to Welsh, but is attested in a range of different languages.

In the sov language Korean, for example, verbal inflections of tense and mood spread to non-final conjuncts just in case they are not marked already on those conjuncts. The data in question is discussed briefly in Choi (1999) who provides the following examples: ${ }^{11}$

a. Mary-ka nolay-lul pwulu-ko Sue-ka chwum-ul chwu-ess-ta. Mary-NOM song-ACC sing-CONJ Sue-NOM dance-ACC dance-PST-DCL

\footnotetext{
${ }^{10}$ This approach develops (and corrects) a suggestion in Choi (1999) concerning coordinate sentences in Korean in which tense (and declarativeness) is marked only on the final verb (this data is illustrated in the following section). Choi's actual proposal suffers from a number of technical difficulties, but the essential idea is clear.

${ }^{11}$ Although she also provides the following example with an apparently shared subject, Choi limits her discussion to cases of tense and mood spread as illustrated in (44)
}

(43) Mary-ka nolay-lul pwulu-ko chwum-ul chwu-ess-ta. Mary-NOM song-ACC sing-CONJ dance-ACC dance-PST-DCL Mary sang a song and danced a dance.(Choi 1999:51,63b) 
Function Spreading in Coordinate Structures:December 11, 2003:

Mary sang a song and danced a dance.(Choi 1999:51,63c)

b. Mary-ka nolay-lul pwulu-ess-ko Sue-ka chwum-ul Mary-NOM song-ACC sing-PST-CONJ Sue-NOM dance-ACC chwu-ess-ta. dance-PST-DCL

Mary sand a song and danced a dance.(Choi 1999:53,65c)

Indeed Choi suggests an analysis of the construction in (44) terms of TENSE and MOOD spreading and a c-structure representation which involves corrdinating S constituents: ${ }^{12}$

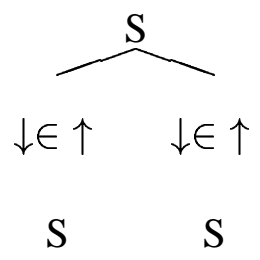

A construction which appears to share some similarities with both the Korean and the Welsh construction is found in Japanese sentences such as (46). In this verb final language TAM information may spread from the final conjunct:

Ojiisan-ga yama-de hatarai-te, obaasan-ga mise-no old man-NOM mountain-at work-and old woman-NOM sotre-GEN ban-o shi-ta to kikimashi-ta. sitting-ACC do-PAST COMP hear-PAST I heard that the old man worked at the mountain, and the old woman tended the store (Yuasa \& Sadock 2002:93 (8))

\footnotetext{
${ }^{12}$ See footnote 10 above.
} 
Function Spreading in Coordinate Structures:December 11, 2003 :

As in Welsh, it seems that any number of conjuncts are possible: ${ }^{13}$

Kenji-ga Oregon-e it-te, Yuki-ga Boston-e it-te Aki-ga

Kenij-NOM Oregon-to go-and Yuki-NOM Boston-to go-and Aki-NOM

Bahamas-e it-ta.

Bahamas-to go-PAST

Kenji went to Oregon, Yuki went to Boston, and Aki went to the Bahamas

(Yuasa \& Sadock 2002:97 (19))

\subsection{Subject Spreading}

In recent work Frank (2002) provides an LFG analysis of the so-called SGF (Subject Gap in Finite/Fronted) coordinate constructions in German. In this construction the subject of the leftmost conjunct is clearly realized in sentence internal position, but is accessible to the second conjunct, and indeed, also serves as subject of that conjunct. A crucial aspect of this construction is that the initial (fronted) constituent is interpreted only with respect to the first conjunct. An example is the following:

In den Wald ging der Jäger und fing einen Hasen. into the forest went the hunter and caught a rabbit The hunter went into the forest and caught a rabbit.

Frank provides extensive discussion of the problems facing existing structurally symmetrical and structurally asymmetrical analyses, and proposes an analysis based

\footnotetext{
${ }^{13}$ One way that the Japanese construction differs from the Welsh construction concerns the order of conjuncts. In an example such as (46), Yuasa \& Sadock (2002) note that the conjuncts can appear in the opposite order ((with -te marking the non-final conjunct(s)). The Welsh construction, on the other hand, seems to require the order of conjuncts to follow a narrative progression.
} 
Function Spreading in Coordinate Structures:December 11, 2003:

on explicit SUBJ sharing, combined with a symmetrical c-structure. The constituent structure she proposes is shown in (49): all the conjuncts are analyzed as CPs with finite verbs appearing in $\mathrm{C}$.

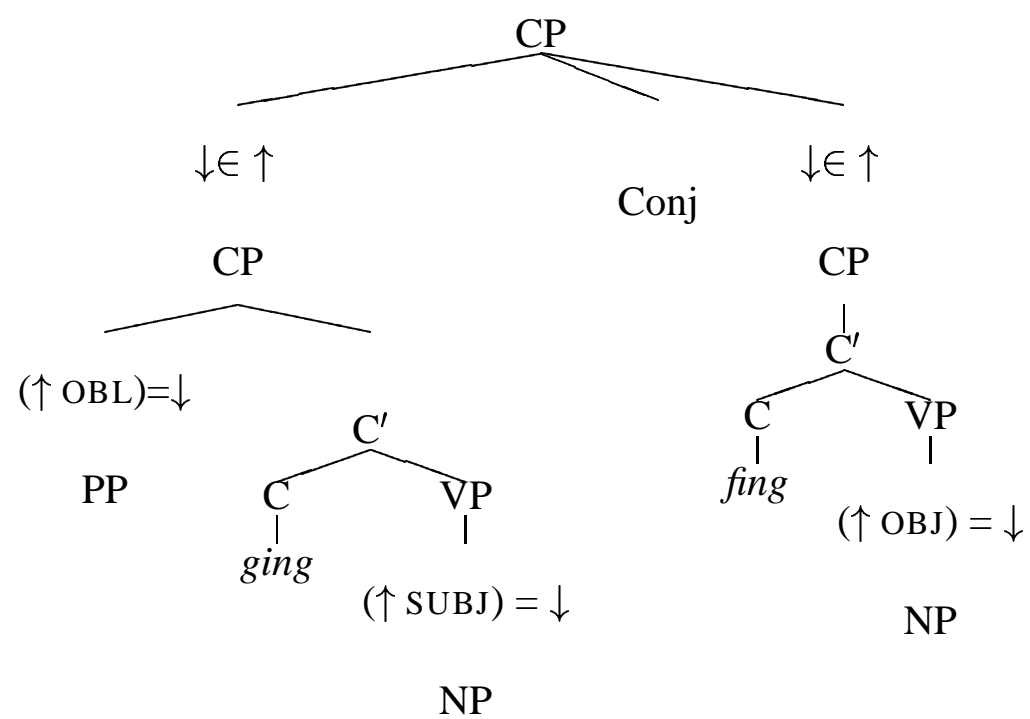

The spreading of the SUBJ is specified in an extension to the standard coordination schema, making reference to the notion grammaticalised discourse function (GDF), and projecting the value of GDF from the first conjunct (thereby spreading it). The GDF are SUBJ, TOPIC, FOCUS, but further constraints interact to limit the choice in this construction to the SUBJ.

$$
\begin{aligned}
& \mathrm{CP} \rightarrow \mathrm{CP} \quad \text { Conj } \mathrm{CP} \\
& \downarrow \in \uparrow \quad \uparrow=\downarrow \quad \downarrow \in \uparrow \\
& (\downarrow \mathrm{GDF})=(\uparrow \mathrm{GDF})
\end{aligned}
$$


Function Spreading in Coordinate Structures:December 11, 2003:

This German construction thus clearly shares with the Welsh construction the fact that it is the subject which is asymmetrically projected, and if Frank's analysis is along the right lines, provides an additional case where the SUBJ may be projected out of a single conjunct.

\subsection{Spreading both Subject and Tense}

Nordlinger (1998) argues that the c-structure of Wambaya, an Australian Aboriginal language, involves a non-projective and nonconfigurational category S under IP. IP accommodates the second position auxiliary, and the order of constituents within $S$ is free. Evidence for the constituent $\mathrm{S}$ includes the existence of nominal clauses, which never contain an auxiliary and are analysed as bare Ss and the possibilities for coordination. In Wambaya, IPs can be coordinated, as shown in (51) and (52).

Manjungu ngirr-a angbardi, nguya ngirr-a shade(ACC) 1PL.EXC.A-PST build(UNM) dig(UNM) 1PL.EXC.A-PST jamba, wugbardi ngirr-a mayinanji ground(ACC) cook(UNM) 1PL.EXC.A-PST goanna(ACC)

We built a shade, (and) we dug (a hole in) the ground (and) we cooked the goanna (Bresnan 2000:138,28a)

(52)

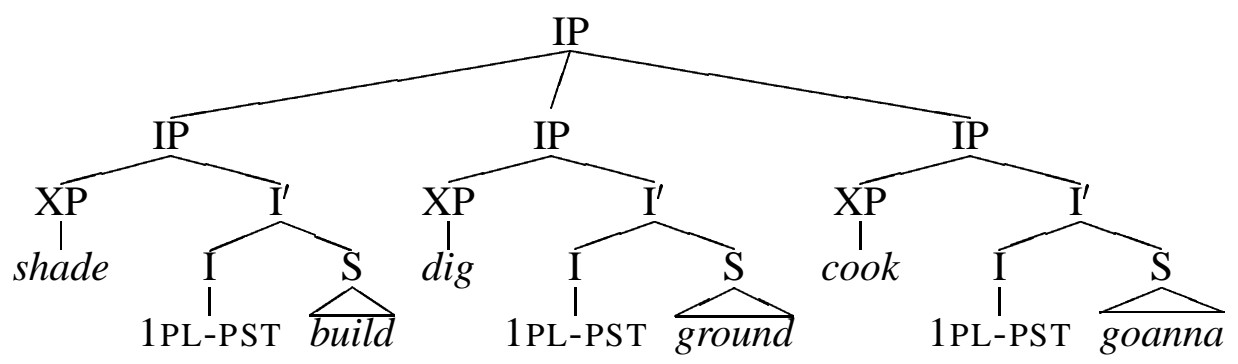


Function Spreading in Coordinate Structures:December 11, 2003:

Alternatively, a pattern exists in which there is only one tensed auxialiary for the coordinate structure as whole (see (53)): Nordlinger and Bresnan (1996) and Bresnan (2000) view this as coordination at the level of S, under I.

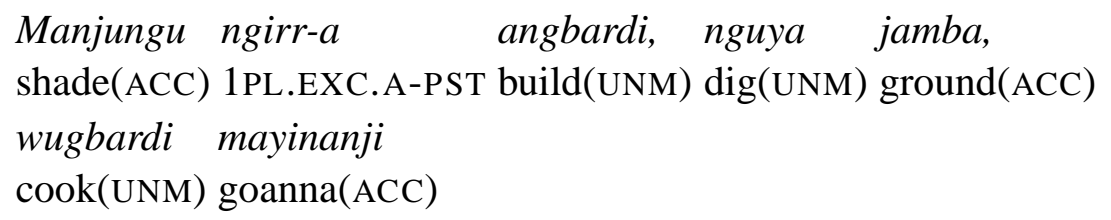

Note however that the c-structure involving $\mathrm{S}$ coordination under I (as shown schematically in (54), would seem to incorrectly distribute the functions associated with the specifier of IP, which is both FOC and OBJ of the first clause, but does not in fact bear any grammatical function at all in the remaining clauses.

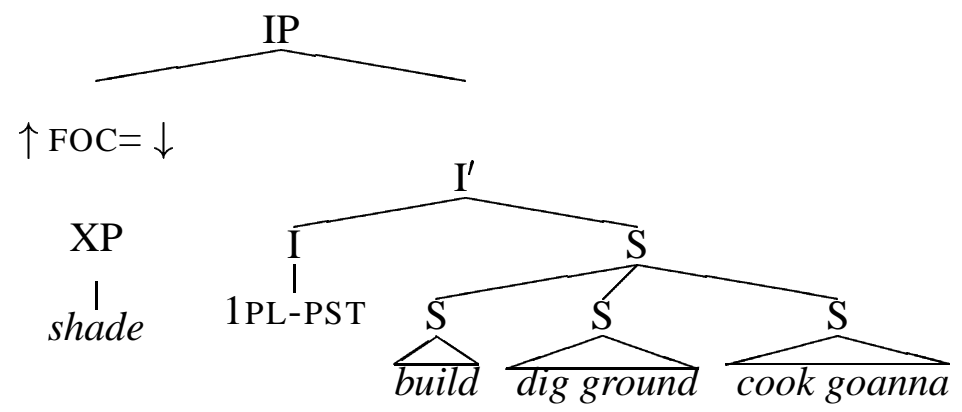

In fact, what seems to distribute here is SUBJ and TENSE suggesting an unlike constitutent coordination analysis (along the lines of our proposal for Welsh) under which non-configurational S is conjoined with an IP, shown schematically in (55) below. 


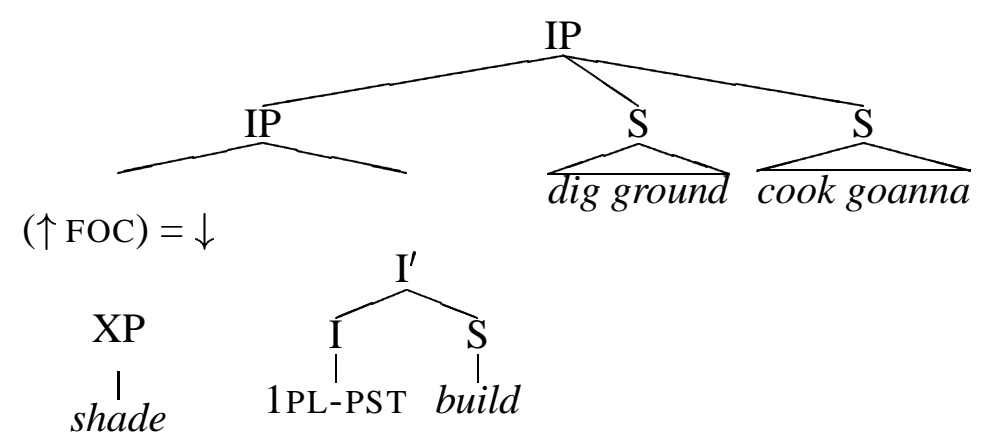

Finally, we turn to a similar pattern in another Celtic language. Although it appears that the tense and subject shared coordination pattern does not occur in Scottish Gaelic and Irish, it does occur in Breton. Breton clasue structure is generally taken to be VSO with V2, with a topicalised initial constituent preceding the finite verb and the subject otherwise preceding the object. In the basic sentential coordination pattern, two main clauses can be juxtaposed using a co-ordinating conjunction, $h a$ 'and', met 'but', pe 'or', na 'nor', rak 'for, because': ${ }^{14}$

Per a ouie neuiñ, mete c'hoarne ouie ket. Peter VPT knew swim but his sister NEG knew BEG Peter was able to swim, but his sister was not' (MacAulay 1992: 396)

When the conjunction is $h a$, 'and', the second verb may occur in uninflected (Verbnoun) form, with a shared subject:

(57) Per a savas ha mont d'ar prenestr. Peter VPT rose and go to the window Peter rose and went to the window (MacAulay 1992: 396)

\footnotetext{
${ }^{14}$ VPT stand for verbal particle.
} 


\section{An Alternative: VP Coordination}

The data reviewed in the previous section shows that there is good cross linguistic evidence for the existence of these sharing equations and also provides further motivation for the symmetrical, unlike constituent structure analysis which we propose. Nonetheless, we did note in section 4 above that an alternative analysis could be considered under which the subject and tensed verb are simply outside the structural scope of coordination. In this section I return to this potential alternative and present some of the theoretical and empirical problems which it faces.

One alternative, then, is to take the fact that tense and subject are shared as indicating that coordination is at the level of VP. On this view, the structure of (32) would be as follows:

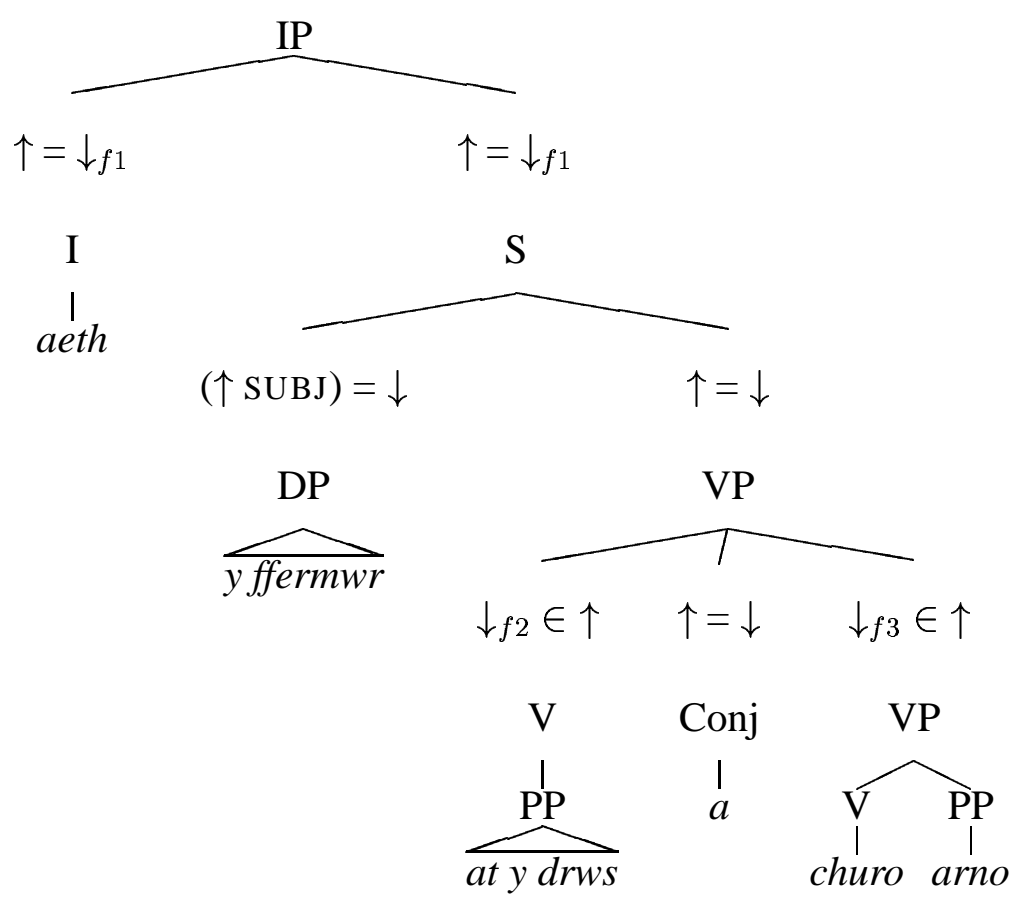


The features SUBJ and TENSE, defined on the set $(f 1)$ of f-structures, would distribute to the f-structures which are members of this set $(f 2, f 3)$, without any further stipulation. However, as we have noted, the PRED value is required neither to distribute nor to be associated with the set itself (in the manner of a non-distributive feature) but to be associated only with the f-structure of the linearly first conjunct. Thus a correct f-structure (38) results neither from treating PRED as distributive, nor from treating it as non-distributive. ${ }^{15}$

In order to associate the PRED value of the tensed verb only with the f-structure of the first conjunct we would require a highly stipulative lexical entry for each tensed verb, for the case where it occurs as the tensed member of a coordinate structure of this sort. The entry must specify firstly that the PRED value that it defines is contributed to a member of a set of f-structures and secondly, that the f-structure to which it contributes a PRED value is the initial conjunct. ${ }^{16}$ This is shown in the lexical entry for the (coordinate use of the) tensed verb aeth in (59):

$$
\begin{aligned}
& \text { aeth: } \\
& \downarrow \in \uparrow \\
& (\uparrow \text { TENSE })=\text { PAST } \\
& (\downarrow \text { PRED })=\text { 'go }<(\text { SUBJ })\left(\mathrm{OBL}_{l o c}\right)>
\end{aligned}
$$

\footnotetext{
${ }^{15}$ If the PRED were distributive, then the equality $(\uparrow \mathrm{PRED})=$ ' $\left.\mathrm{go}<(\uparrow \mathrm{SUBJ})\left(\uparrow \mathrm{OBL} \mathrm{loc}_{l o}\right)\right\rangle$ ' would be specified for each of the set of f-structures, resulting in a constant-constant clash, since the non-initial conjuncts have their own PRED values.

${ }^{16}$ More obscurely, it might also be necessary to ensure that the PRED equation does not itself actually introduce an additional member into the set of f-structures.
} 
Function Spreading in Coordinate Structures:December 11, 2003:

$$
\forall x, x \neq \downarrow \wedge x \in \uparrow, \downarrow<{ }_{f} x
$$

In (59) the membership statement specifies that the f-structure of aeth is a member of a set of f-structures. The following functional equation contributes a TENSE value to the $\mathrm{f}$-structure $\uparrow$ (which in the case of $(58)$ is $f 1$ ): since this is a set, the TENSE specification is distributed to all the members of the set ( $f 2$ and $f 3$ ). The functional equation for PRED contributes a PRED value to that f-structure $\downarrow$ - the f-structure denoted by $\downarrow$ will have to be identified with a member of the set of f-structures. The final, rather complicated, statement captures the fact that aeth contributes to the initial conjunct by requiring that the f-structure of aeth (that is, the f-structure $\downarrow$ ) fprecedes all the other f-structures in the set corresponding to the coordinate structure. The definition of f-precedence is as follows:

(60) Given a correspondence mapping $\phi \ldots$ between a c-structure and its fstructure, and given two subsidiary f-structures $\alpha$ and $\beta, \alpha$ f-precedes $\beta$ if the rightmost node in $\phi^{-1}(\alpha)$ precedes the rightmost node of $\phi^{-1}(\beta)$ (Bresnan 2000:195)

There are several theory internal reasons for rejecting this style of analysis, despite the fact that it might be techically formulatable. Firstly, it is very clumsy, and this singular lack of elegance probably indicates that it is not along the right lines. Secondly, it does not seem to cohere correctly with current assumptions about endocentricity in strongly configurational languages such as Welsh. The basic property of 
Function Spreading in Coordinate Structures:December 11, 2003:

endocentricity is that every category has a head that determines its properties. When a finite verb occurs in I rather than V, as in Welsh simple clauses, the VP lacks an internal head, but as we noted above, this is not a violation of endocentricity, for amongst those nodes in the inverse image of $\phi(\mathrm{VP})$, the closest nondominating node to VP can be identified as the head (see footnote 3 above for the definition of extended head). If the I node is not the extended head of VP2 in (58) then it lacks a head, in violation of a basic assumption about configurational structure.

In addition, there is further, empirical evidence preferring the feature-spreading analysis over the VP coordination analysis. This concerns the predictions the two analyses make about material fronted before the finite verb. (61 a) (the VP coordination analysis) predicts that fronted material distributes into each conjunct, while the features-spreading analysis in (61 b) analysis) predicts that fronted material is associated only with the first conjunct. ${ }^{17}$

(61)

(a)

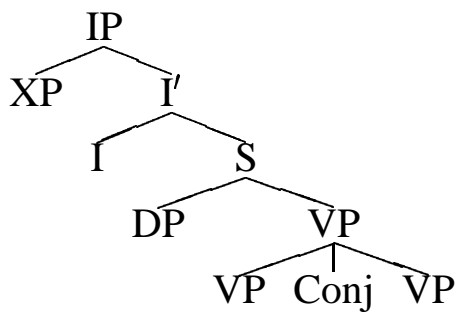

(b)

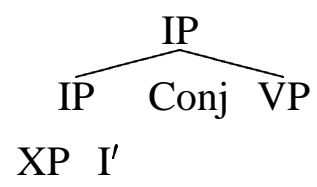

Consider now the sentences in (62)-(64):

I'r thy yr aethant ac eistedda bwyta. to-the house PT go-PAST.3PL and sit.VN and eat.VN

\footnotetext{
${ }^{17}$ In each case, we are concerned with fronted material appearing in the Spec of IP.
} 
Function Spreading in Coordinate Structures:December 11, 2003 :

(It was) to the house they went and sat and ate. ${ }^{18}$

Aty drws yr aeth $\quad y$ ffermwra churo arno.

to the door PT go-PAST.3s the farmer and knock on-3s

(It was) to the door that the farmer went and knocked on it.

(64) I'r wardy daeth Dr Konradun bore a'm gweld to-the ward PT come-PAST.3S Dr Konrad one morning and-1s see

i'n gwylio'r gwenoliaid.

1s-PROG watch-the seagulls.

(It was) to the ward that Dr Konrad came one morning and saw me watching the seagulls.

In these examples, it is clear that the fronted constituent bears a grammatical function in the first conjunct, but not in the following conjuncts. This follows automatically on the feature-spreading analysis, since it is within the first conjunct under this analysis. In the VP coordination analysis, on the other hand, the I node is outside the scope of coordination, and so necessarily is a constituent preceding the finite verb in I. The analysis therefore makes the wrong empirical prediction here, facing much the same difficulty as we noted arises for the like-constituent coordination analysis of the Wambaya (53), shown in (52) above.

\footnotetext{
${ }^{18}$ Thanks for informant judgements to Dwyryd and Bethan and to Tony Platt.
} 


\section{Conclusion}

This paper has proposed an analysis of a particular asymmetricl coordination pattern in Welsh, in which both tense and a subject are expressed only in the first clause. Working in the constraint-based framework of LFG, and in particular using the approach to coordination offered in that theory, we show how a straightforward analysis of this construction can be given by positing explict "spreading" equations associated with the first conjunct. The "spreading" analysis of the Welsh data presented here is supported by data from a range of languages which also spread clausal features (such as TENSE and MOOD), the SUBJ function, or both clausal features and the SUBJ. Finally, we have shown that the alternative analysis, involving VP coordination under a shared finite verb and subject DP, suffers from a number of theoretical and empirical difficulties.

/home/welsh/coordination/tenseless/tense-share2.tex

\section{Bibliography}

Borsley, R. D. 1994. In Defense of Coordinate Structures. Linguistic Analysis 24(3-4):218-246.

Bresnan, J. 2001. Lexical Functional Syntax. Oxford: Blackwell.

Choi, H.-W. 1999. Optimizing Structure in Context. Stanford: CSLI Publications. 
Function Spreading in Coordinate Structures:December 11, 2003:

Dalrymple, M. 2001. Lexical Functional Grammar. San Diego, CA: Academic Press.

Frank, A. 2000. A (discourse) functional analusis of asymmetric coordination. In M. Butt and T. H. King (Eds.), Proceedings of the LFG02 Conference, Stanford, CA. CSLI Publications: http://www-csli.stanford.edu/publications.

Nordlinger, R. 1998. Constructive Case: Evidence from Australian Languages. Stanford, CA: CSLI Publications.

Nordlinger, R., and J. Bresnan. 1996. Nonconfigurational tense in Wambaya. In M. Butt and T. H. King (Eds.), Proceedings of LFG96, Stanford, CA. CSLI Publications: http://www-csli.stanford.edu/publications.

Rouveret, A. 1994. Le syntaxe du gallois. Paris, France: Editions CNRS.

Sadler, L. 2003. Coordination and Asymmetric Agreement in Welsh. In Miriam Butt and Tacy Holloway King (Ed.), Nominals: Inside and Out. Stanford, CA: CSLI.

Thomas, P. W. 1996. Gramadeg y Gymraeg. Caerdydd: Gwasg Prifysgol Cymru.

Thorne, D. A. 1993. A Comprehensive Welsh Grammar. Oxford: Blackwells.

Yuasa, E., and J. Sadock. 2002. Pseudo-subordination: a mismatch between syntax and semantics. Journal of Linguistics 38:87-111. 